\title{
Experimental Study on CRI Technology in the Degradation of COD in Wastewater Reuse
}

\author{
Pengshuai Qiao*
}

North China University of Water Resources and Electric Power, Zhengzhou 450045, China

\begin{abstract}
With the improvement of the urbanization level, the mixed city water has surged and the traditional denitrogenating cost in the course of wastewater reuse has been unbearable. This experiment used the technology of the constructed rapid infiltration (CRI) and applied the soil column simulation method in the laboratory. The results show that nitrogen removal rates of two soil columns are $73.73 \%-75.54 \%, 66.70 \%-77.81 \%$ and $79.33 \%-73.08 \%$ under three wet/ dry $(3 \mathrm{~h} / 9 \mathrm{~h}, 6 \mathrm{~h} / 18 \mathrm{~h}, 8 \mathrm{~h} / 40 \mathrm{~h})$ ratios conditions, individually. The same soil column with the same wet/ dry ratio has a higher ammonia nitrogen removal rate within a shorter operation time. The comparison result of experiments show that the artificial soil mixture ratio in column 2 is better than that of column 1, arriving at the optimum operation conditions of the system.
\end{abstract}

Keywords: Ammonia nitrogen, constructed rapid infiltration, soil column simulation, wastewater reuse.

\section{INTRODUCTION}

With the increased demand for our food, food production has become increasingly dependent on irrigation. On the one hand, resource-based and water-type water shortages are increasingly restricting the development of agricultural production; on the other hand, a large number of phosphorus, nitrogen and organic pollutants in urban sewage discharge caused serious pollution to the environment. The land irrigation and sewage land treatment technology are organically combined. It could take full advantage of the wastewater land treatment technology and overcome the drawbacks of traditional wastewater irrigation, thus reducing pollution, treating the sewage, saving water resources, and ensuring the production and quality of crops. Water and fertilizers are fully utilized to increase crops' production. Wastewater is recycled as a resource, promoting the benign water resource circulation between natural and social systems [1]. In the late 20 th century, many countries in the world tried to use reclaimed municipal wastewater for agricultural irrigation and made some achievements. For example, in the United States and Israel, 60\% urban recycling water has been used for agricultural irrigation [24]. The author designed a set of artificial rapid infiltration (CRI) indoor simulation test system for urban sewage treatment, which can reach the general crop irrigation water standard, thus achieving the maximum environmental, economic and social benefits of the urban wastewater resources.

*Address correspondence to this author at the No.36, Beihuan Road, North China University of Water Resources and Electric Power, Zhengzhou, 450045, China; Tel: +8613663713695; E-mail: 675781472@qq.com

\section{MATERIALS AND METHODOLOGY}

\subsection{Test Materials and Equipment}

Simulation test system consists of two plexiglass tubes with the inner diameter of $19 \mathrm{~cm}$, length of $190 \mathrm{~cm}$. The bottom of the glass tube is supported by a steel frame; the bottom of the pipe is laid by $10 \mathrm{~cm}$ thick pebbles, with smaller gravels upwards, artificial prepared soil. The preparation of artificial soil is compacted once every $10 \mathrm{~cm}$, the artificial soil layer about $150 \mathrm{~cm}$ thick. The uppermost column is also filled with gravels; layers are separated with nylon net pad (see Fig. 1). The position of the sampling port is shown in Table $\mathbf{1}$.

In order to compare the pollutants removal effects of the artificial soil with different compositions and ratios, water is simultaneously injected and sampled to test the water quality. The artificial soil in column 1 is composed of natural river sand (sieved with a $2 \mathrm{~mm}$ sieve mesh), topsoil soil, fine slag and peat; the artificial soil in column 2 is composed of natural river sand, topsoil soil and peat (fine slag in column 1 is changed into peat with equal weight). The test adopted three different wet/dry ratio cycles, respectively $3 \mathrm{~h} / 9 \mathrm{~h}, 6 \mathrm{~h}$ $/ 18 \mathrm{~h}$ and $8 \mathrm{~h} / 40 \mathrm{~h}$, each wet/dry ratio running 6 cycles.

Test water is the mixed wastewater of the Dongfeng Ditch of Zhengzhou (North Third Ring Road to Garden Road section). The water source is mainly composed of the domestic wastewater, and little industrial wastewater. Water is collected and taken back to the lab, removed from large particulate matters through the still settlement, filtered by a filter screen with a diameter of $0.5 \mathrm{~mm}$. The suspended matters are removed to avoid the obstruction [5]. The lab test result shows that the removal effect of the domestic wastewater through the pre-treatment mainly appears in the 


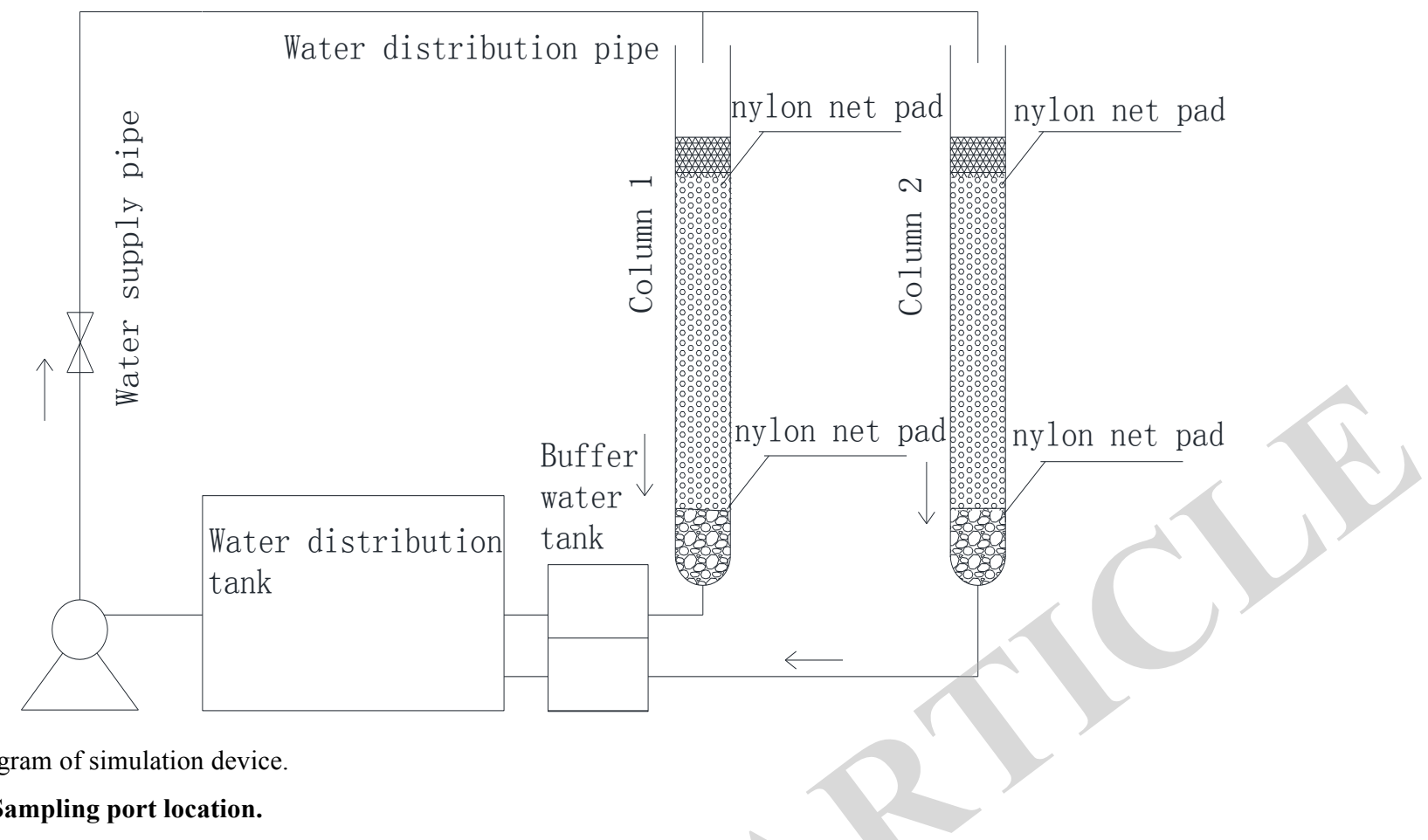

Fig. (1). Diagram of simulation device.

Table 1. Sampling port location.

\begin{tabular}{|c|c|c|c|}
\hline Sampling Port Name of Column 1 & Distance from the Soil Surface/cm & Sampling Port Name of Column 2 & Distance from the Soil Surface/cm \\
\hline \hline $1-1$ & 25 & $2-1$ & 25 \\
\hline $1-2$ & 75 & $2-2$ & 75 \\
\hline $1-3$ & 150 & $2-3$ & 150 \\
\hline
\end{tabular}

first 12 hours [6]. The COD concentration amounts of three wet/dry ratios are respectively $300.04 \mathrm{mg} / \mathrm{L}, 302.47 \mathrm{mg} / \mathrm{L}$ and $302.2 \mathrm{mg} / \mathrm{L}$, which exceed the COD concentration standard $(100.00 \mathrm{mg} / \mathrm{L})$ of the general crop irrigation (according to the farmland irrigation water quality standard, GB5084-2005). This indicates that untreated wastewater cannot be used in general crop irrigation.

\subsection{Test Principle}

The COD removal mechanism of the CRI system mainly includes volatilization, adsorption, chemical and biological degradation and so on. Organic substances in the CRI system are mainly made by biodegradation. The organic matter trapped in the soil promotes the propagation of microorganisms, which further absorb, forming a biofilm composed of the floc and a large number of fungal hyphae; when organic matters are degraded, the biofilm is continually updated due to metabolism, keeping the longterm pollutants degradation and removal functions $[7,8]$.

The COD concentration ratio between the wastewater and processed wastewater is used to test the purification ability of soil, i.e., $\mathrm{C} / \mathrm{C} 0 . \mathrm{C} 0$ is the $\mathrm{COD}$ concentration of the wastewater; $\mathrm{C}$ is the $\mathrm{COD}$ concentration of the processed wastewater. When the $\mathrm{C} / \mathrm{C} 0$ value is less than 0.2 , soil can be an effective treatment for wastewater, when $\mathrm{C} / \mathrm{C} 0$ is larger than 0.2 , the treatment effect of soil would be significantly reduced [9].

\subsection{Test Analysis}

The COD concentrations of the influent and effluent are tested by the potassium dichromate. Water sample is injected above with a constant flow device and flows out from the bottom column outlet. Effluent concentrations of all outlets with three wet/dry ratios are tested, seen from Figs. (2-7).

As can be seen from Figs. (2-7), during the initial operation of the CRI system, since the microorganisms have not fully matured, the degradation of COD in wastewater is mainly made by physical and chemical interception and adsorption of the artificial soil, which appeared the convergence of changes between influent and effluent COD concentrations. Studies have shown that the total removal rate of $\mathrm{COD}$ through non-biodegradation (e.g. physical sedimentation and filtration in the soil; chemical adsorption, decomposition, precipitation, ion exchange, oxidation, reduction and other chemical reactions, etc.) was $55.1 \%$ on average, while the removal rate of COD through purely mechanical retention and adsorption is 48.9\% [10]. However, with the extension of operation time, the mechanical retention and chemical absorption of COD would gradually achieve saturation, resulting in a reduction of COD purification capacity. Then the growth of microorganisms in CRI utilizes carbonaceous compounds in wastewater, which increases the biodegradation of COD in CRI. Therefore, the removal of organic contaminants is the result of biological and non-biological interaction. The organic matter is mechanically trapped by soil and is mainly 
biologically degraded. Only a small part is removed through absorption $[11,12]$. Thus, with the extension of operation time, COD concentration in wastewater is within some certain extent. COD concentration in the processed water is gradually stabilized, which is shown in Figs. $(\mathbf{8}, \mathbf{9})$.

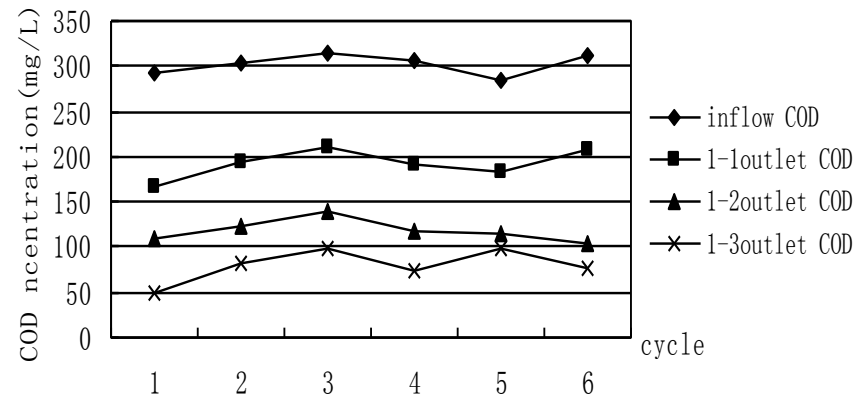

Fig. (2). Influent and effluent COD concentrations of $3 \mathrm{~h} / 9 \mathrm{~h}$ in column 1 .

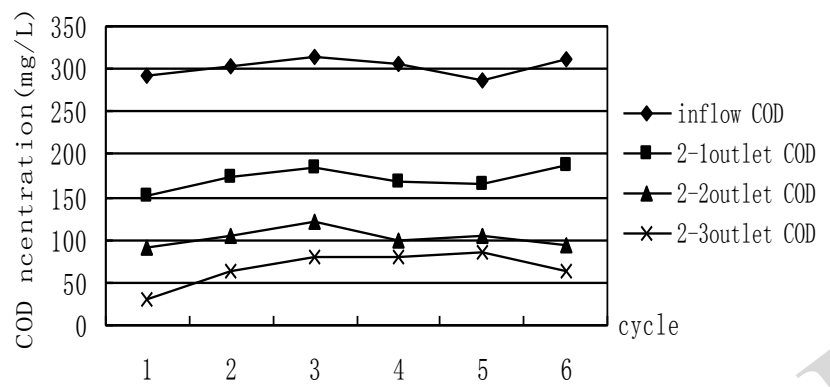

Fig. (3). Influent and effluent COD concentrations of $3 \mathrm{~h} / 9 \mathrm{~h}$ in column 2.

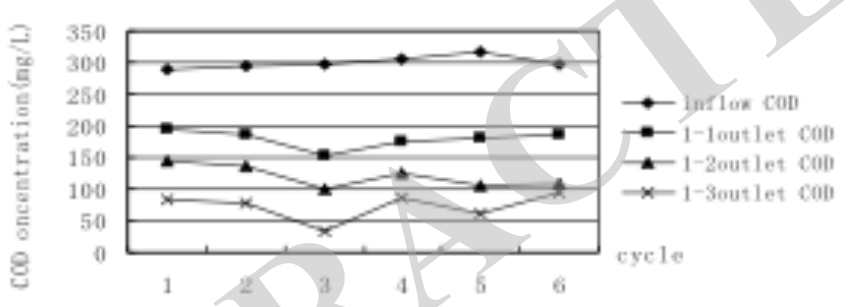

Fig. (4). Influent and effluent COD concentrations of $6 \mathrm{~h} / 18 \mathrm{~h}$ in column 1 .

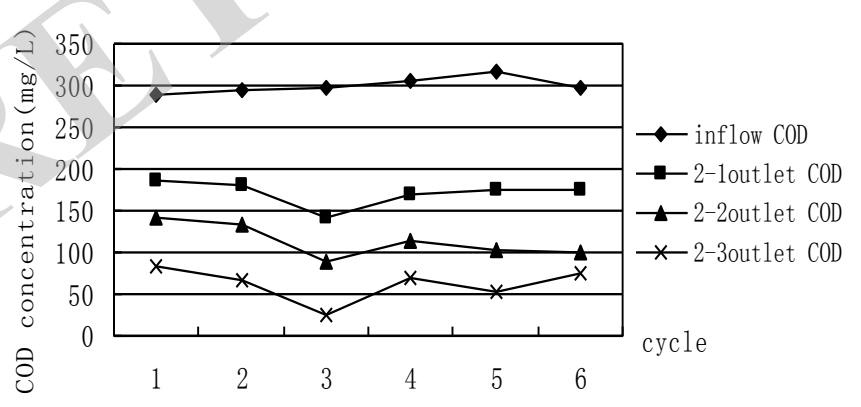

Fig. (5). Influent and effluent COD concentrations of $6 \mathrm{~h} / 18 \mathrm{~h}$ in column 2.

Figs. (8, 9) indicate the following contents: (1) The first two wet/dry ratio is 1: 3 , only with different operation time. The third wet/dry ratio is $1: 5$, the ratio being the larger, $(1: 3$ $>1: 5$ ), COD removal rate becoming higher. (2) With the same wet/dry ratio, the removal rate of COD in column 2 is higher than column 1, indicating that the artificial soil is superior than that of column 1 . After 6 operation cycles with 3 wet/dry ratios, effluent COD at the column bottom are shown in Table 2.

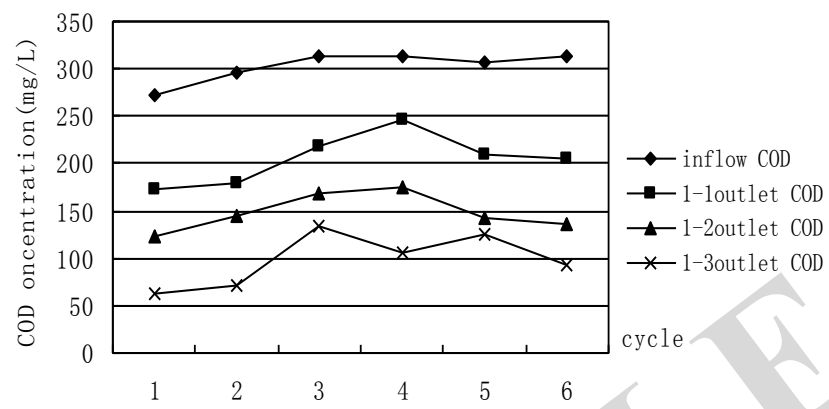

Fig. (6). Influent and effluent COD concentrations of $8 \mathrm{~h} / 40 \mathrm{~h}$ in column 1 .

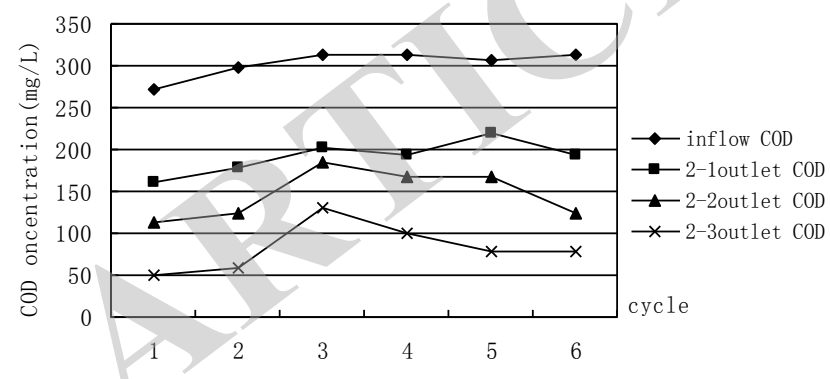

Fig. (7). Influent and effluent COD concentrations of $8 \mathrm{~h} / 40 \mathrm{~h}$ in column 2 .

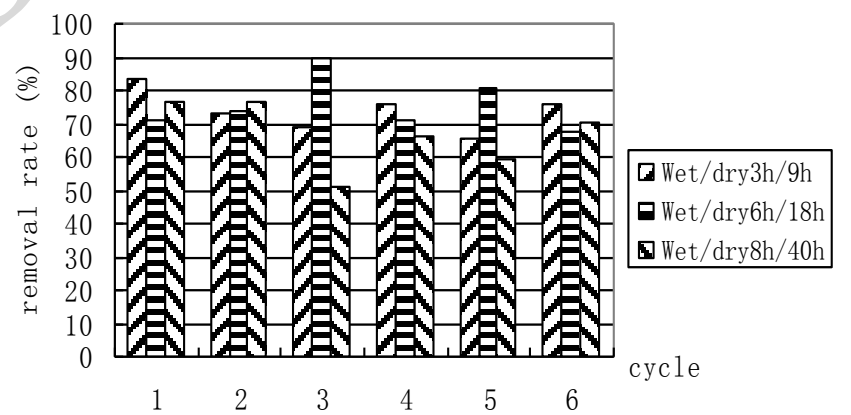

Fig. (8). COD removal rates with different wet/dry ratio in column 1.

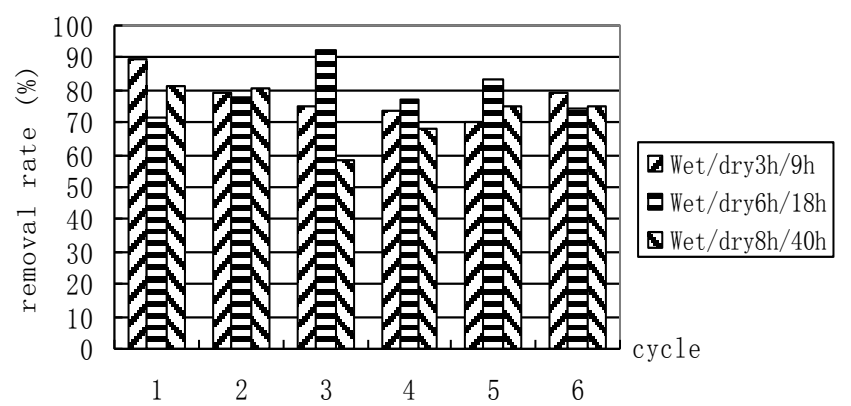

Fig. (9). COD removal rates with different wet/dry ratio in column 2 .

As can be seen from Table 2, with different wet/dry ratios, the effluent COD concentration is less than $100 \mathrm{mg} /$ $\mathrm{L}$, meeting the standard of general crop irrigations. 
Table 2. COD of the bottom outlet water with three wet/dry ratios.

\begin{tabular}{|c|c|c|c|}
\hline Column Name & $\begin{array}{c}\mathbf{3} \mathbf{~ h} / \mathbf{9} \mathbf{h} \\
\text { Wet/Dry Ratio }\end{array}$ & $\begin{array}{c}\mathbf{6} \mathbf{~ h} / \mathbf{1 8} \mathbf{~ h} \\
\text { Wet/Dry Ratio }\end{array}$ & $\begin{array}{c}\mathbf{8} \mathbf{~ h} / \mathbf{4 0} \mathbf{~ h} \\
\text { Wet/Dry Ratio }\end{array}$ \\
\hline \hline Column 1 & 79.35 & 73.41 & 98.49 \\
\hline Column 2 & 67.09 & 61.95 & 82.22 \\
\hline
\end{tabular}

As can be seen from the above test results, reducing the submerging time or increasing the drying time can increase the amount of oxygen, increase the microbial activity, which is conducive to the COD degradation. Under the same hydraulic loading conditions, shortening the hydraulic loading cycle, increasing the dosing frequency during the system operation, reduce the amount of wastewater dosing, increase the reoxygenation efficiency, avoid the saturation due to over-absorption of pollutants, increase the possibility of pollutant penetration, thus ensuring the stable effluent quality. Under conditions of three wet/dry ratios, the removal rate of COD in column 2 is higher than column 1 . The main reason is that the large amount of peat in column 2 has strong absorption capacity and contains more microorganisms. Thus, increasing the peat in artificial soil could increase the removal rate of COD.

\section{CONCLUSION}

Based on the above test results, it can be seen that the present system has a better effect of COD treatment. With three wet/dry ratios $(3 \mathrm{~h} / 9 \mathrm{~h}, 6 \mathrm{~h} / 18 \mathrm{~h}, 8 \mathrm{~h} / 40 \mathrm{~h})$, the average effluent COD concentrations in column 1 are respectively $73.73 \%, 75.54 \%$ and $66.70 \%$; those in column 2 are respectively $77.81 \%, 79.33 \%$ and $73.08 \%$. The effluent COD concentration at the column bottom is in full compliance with the general standard of crop irrigations. The removal rate of COD in column 2 is significantly higher than column 1 , indicating the importance of selecting the appropriate media in pollutant removal. The reduction of operation cycles has no obvious effects on the removal rate. Therefore, during the wastewater resource, if the effluent quality meets the standard of irrigation water, extending the operation cycle properly could increase the hydraulic loading, thus resulting in the maximum environmental, social and economic benefits.

\section{CONFLICT OF INTEREST}

The author confirms that this article content has no conflict of interest.

\section{ACKNOWLEDGEMENTS}

Henan Research Project of Science and Technology (04240900181); Scientific and Technological Foundation of Zhengzhou (10PTGSS507); Natural Science Research Program of Henan Education Department in 2011 (2011B570005); Special Appropriation in Science and Technology of Guizhou Water Resources Department (KT201313).

\section{REFERENCES}

[1] P. S. Qiao, "Water quality test and theory research of wastewater irrigation from DongFeng Dich", Zhengzhou: North China Institute of Water Conservancy and Hydropower, 2006.

[2] W. H. Xiao, Y. Cai, H. L. Wang, and P. Li, "Advances in Study on Reclaimed Wastewater Utilization in Agriculture", South-to-north water transfers and water scince\& technology, vol. 7, no. 4, pp. 98100, 2009.

[3] Z. L. Liu, "The Dynamic Analysis of China's Energy-EconomyEnvironment System: VAR and VEC Modeling", Advances in Information Sciences and Service Sciences, vol. 4, no. 14, pp. 210218, 2012.

[4] P. S. Qiao and H. J. Zhao, "Experimental Study on CRI Technology in the Degradation of Ammonia Nitrogen in Wastewater Reuse", Yellow River, vol. 35, no. 8, pp. 46-49, 2013.

[5] J. B. Zhang, "Artificial Rapid Infiltration Treatment System of Wastewater in Dongguan Huaxing Electric Appliance Factory", Environmental Engineering, vol. 21, no. 6, pp. 32-36, 2003.

[6] X. Z. Cheng, "The Present Status and Improvement of the Soil Infiltration Technology", Environmental Sciences, vol. 12, no. 4, pp. 33-36, 1999.

[7] D. F. Guo and A. X. Jiang, "Application of Wastewater Land Treatment System", Environmental Science, vol. 3, no. 6, pp. 64-70, 1995.

[8] Y. L. Wang, "Study on design parameter of industrial wastewater rapid land treatment system", Environmental Engineering, vol. 2, no. 19 , pp. $20-23,2001$.

[9] H. Li and J. L. Wang, "Sewage Treatment Characteristics of the Land", Northern Environmental, vol. 29, no. 5, pp. 36-38, 2004.

[10] T. H. Sun and S. Y. Zhou, "The Technology Guide of the Municipal Wastewater Land Treatment", Beijing: China Environmental Science Press, 1997.

[11] United States Environmental Protection Agency, Process Design Manual for Land Treatment of Municipal Wastewater, Cincinnati, Ohio: U S Environmental Protection Agency Center for Environmental Research Information, 1981. 